\title{
ARTIGO
}

DOI: $10.22481 /$ praxis.v14i27.2926

\section{DIMENSÕES A SEREM CONSIDERADAS PARA A DISCUSSÃO DE POLÍTICAS EDUCACIONAIS NA REALIDADE AMAZÔNICA}

\author{
DIMENSIONS TO BE CONSIDERED FOR THE DISCUSSION OF EDUCATIONAL \\ POLICIES IN THE AMAZONIAN REALITY
}

\author{
DIMENSIONES A CONSIDERAR PARA LA DISCUSIÓN DE POLÍTICAS EDUCATIVAS \\ EN LA REALIDAD AMAZÓNICA
}

Ana Elisa Spaolonzi Queiroz Assis Universidade Estadual de Campinas - Brasil

\author{
José Roberto Rus Perez \\ Universidade Estadual de Campinas - Brasil \\ Universidade Federal do Oeste do Pará - Brasil
}

Maria Lília Imbiriba Sousa Colares

Universidade Federal do Oeste do Pará - Brasil

\begin{abstract}
Resumo
No contexto de uma pesquisa financiada no escopo do Programa de Cooperação Acadêmica - PROCAD e nomeada "As Experiências Pedagógicas das Políticas de Educação Integral na Amazônia: Rede de Pesquisa e Formação Acadêmica" envolvendo três Universidades (Universidade Estadual de Campinas UNICAMP; Universidade Federal de Rondônia - UNIR e Universidade Federal do Oeste do Pará UFOPA), este trabalho visa a parte norte do Brasil, em particular a cidade de Santarém, no estado do Pará. Nosso objetivo é problematizar e refletir sobre a relação entre três dimensões: socioeconômica, educacional e ambiental, que, embora apresentadas separadamente, são imbricadas e devem ser consideradas em uma perspectiva dialógica na discussão das políticas educacionais na realidade amazônica. A metodologia baseia-se em pesquisa bibliográfica e documental, de modo que os dados apresentados são oriundos de órgãos públicos nacionais e estaduais. Portanto, a estrutura do artigo possui uma introdução para apresentar a área onde o estudo é conduzido, seguido da exposição dos dados de cada dimensão, terminando com algumas considerações para discutir políticas públicas educacionais na região amazônica.
\end{abstract}

Palavras Chave: Políticas Públicas. Amazônia. Educação.

\begin{abstract}
In the context of an ongoing financed research named Academic Cooperation Program (Programa de Cooperação Acadêmica) - PROCAD "The Pedagogical Experiences of the Integral Education Policies in Amazon Region: Research Network and Academic Training" involving three Universities (State University of Campinas - UNICAMP; Federal University of Rondônia - UNIR; and Federal University of the West of Pará - UFOPA) this work aim at the north part of Brazil, particularly the city of Santarém in the state of Pará. Our goal is to problematize and reflect about the relation between three dimensions: socioeconomic, educational and environmental, that although presented separately, are imbricated and should be considered in a dialogical perspective in the discussion of educational policies in the Amazonian reality. The methodology is based on bibliographical and documentary research, so that the data presented here come from national and state public agencies. Therefore, the structure of the paper is going to have an
\end{abstract}


introduction, to present the area where the study is conducted, followed by data from each dimension, ending with some considerations that must take place in order to discuss public educational policies in the Amazon region.

Key words: Public Policies. Amazon. Education.

\section{Resumen}

En el contexto de una investigación financiada en el contexto del Programa de Cooperación Académica (Programa de Cooperación Académica) - PROCAD, denominada "Las experiencias pedagógicas de las políticas educativas integrales en la región amazónica: Red de investigación y formación académica" en tres universidades (Universidad Estatal de Campinas - UNICAMP; Universidad Federal de Rondônia UNIR y Universidad Federal del Oeste de Pará - UFOPA) este artículo tiene como foco la parte norte de Brasil, en particular la ciudad de Santarém en el estado de Pará. Nuestro objetivo es problematizar y reflexionar sobre la relación entre tres dimensiones: socioeconómica, educativa y ambiental, que aunque presentadas por separado, son imbricadas y deben ser consideradas desde una perspectiva dialógica en la discusión de las políticas educativas en la realidad amazónica. La metodología se basa en la investigación bibliográfica y documental, por lo que, los datos presentados aquí provienen de agencias públicas nacionales y estatales. Por lo tanto, la estructura del documento tendrá una introducción, para presentar el área donde se realiza el estudio, seguido de datos de cada dimensión, finalizando con algunas consideraciones que deben tener lugar para discutir las políticas educativas públicas en la región amazónica.

Palabras clave: Políticas Públicas. Amazônia. Educación.

\section{Introdução}

Descobrimento

Abancado à escrivaninha em São Paulo Na minha casa da rua Lopes Chaves De supetão senti um friúme por dentro.

Fiquei trêmulo, muito comovido

Com o livro palerma olhando pra mim.

Não vê que me lembrei que lá no Norte, meu Deus! muito longe de mim

Na escuridão ativa da noite que caiu Um homem pálido magro de cabelo escorrendo nos olhos, Depois de fazer uma pele com a borracha do dia,

Faz pouco se deitou, está dormindo.

Esse homem é brasileiro que nem eu.

Mário de Andrade

No final do século XX, a questão do desenvolvimento sustentável garante espaço de destaque nas agendas de órgãos internacionais e ganha força ao longo do tempo de forma a não só fazer-se presente nas agendas políticas micro e macro dos países, mas também na elaboração e 
implementação de programas locais, regionais, nacionais e transnacionais que tenham a temática como foco.

Atualmente, dentre muitas outras iniciativas, está a Agenda 2030 para o Desenvolvimento Sustentável encabeçada pela Organização das Nações Unidas (ONU) em 2015, contendo 17 objetivos e 169 metas postas em marcha desde de janeiro de 2016. Diretamente relacionada com o problema que queremos discutir, qual seja, políticas educacionais no contexto da floresta amazônica na cidade de Santarém - PA/Brasil está o objetivo 4 do referido documento: "Assegurar a educação inclusiva e equitativa e de qualidade, e promover oportunidades de aprendizagem ao longo da vida para todos”. Neste contexto, apesar das diversas ações realizadas em todo o país, por diferentes órgãos, com destaque para a Campanha Nacional pelo Direito à Educação que conduz a Semana da Ação Mundial $\left(\mathrm{SAM}^{1}\right)$, é importante sopesar que para além das atividades globais e nacionais, é preciso pensar em ações regionais e locais, em especial quando se trata de um país com proporções continentais que abarcam não só uma grande diversidade de biomas, mas também de situações socioeconômicas.

Nossa hipótese de trabalho gira em torno do reconhecimento de que para a política pública educacional surtir efeitos, é ponderar mais do que questões pedagógicas/educacionais, relacionando-as com aspectos socioeconômicos e ambientais, já que discussões localizadas são insuficientes frente o cenário presente em lugares como Santarém.

Nesse sentido, considerando que a administração tradicional é incapaz de garantir o desenvolvimento sustentável e que o mundo globalizado permite a aproximação entre cidades que enfrentam problemas semelhantes, o objetivo do presente trabalho não é determinar qual seria a melhor política educacional, mas problematizar e refletir sobre a relação entre três dimensões: socioeconômica, educacional e ambiental, visando aspectos para uma política pública intersetorial articulada pretendendo efetivar inclusão e equidade.

No Brasil, embora negligenciado com certa constância, temos um terreno normativo bastante fértil que permite a convergência de dimensões socioeconômica, educacional e ambiental para implementação de políticas públicas. A Política Nacional de Recursos Hídricos (Lei n. ${ }^{\circ} 9.433$ de 1997) demanda que a unidade de planejamento e gerenciamento seja a bacia hidrográfica, o que dá margem a um pensamento distinto, pois não considera mais as delimitações artificiais entre municípios e estados que, com os processos de conurbação, vão criando novas e outras relações

\footnotetext{
1 A SAM, iniciativa lançada pela Campanha Global pela Educação (CGE), embora exista desde 2003, estava anteriormente vinculada ao Programa Educação para Todos da Organização das Nações Unidas para a Educação, a Ciência e a Cultura (UNESCO), mas desde a aprovação da Agenda 2030, vinculou-se a ela objetivando exercer pressão sobre os governos para que cumpram os acordos internacionais da área, envolvendo atualmente mais de 100 países.
} 
com o território. Soma-se a isso, o conceito de "bacia ambiental" enquanto "unidade para planejamento ambiental estratégico para as águas doces metropolizadas sob a perspectiva da sustentabilidade do desenvolvimento" (RUTKOWSKI, 1999 p.4).

Ao criar este conceito, a autora dá vida à bacia hidrográfica, vez que reconhece nela a existência de ações antrópicas dos mais variados tipos, sendo "um espaço territorial de conformação dinâmica, cujos limites são estabelecidos pelas relações ambientais de sustentabilidade de ordens ecológica e social” (RUTKOWSKI, 1999 p.135). Ademais, a premissa fundamental da bacia ambiental é "a viabilização da qualidade de vida acordada entre os diversos segmentos sociais que habitam sua terra" (RUTKOWSKI, 1999 p.136).

A despeito de entendermos que qualquer cidade possa ser lócus de uma discussão de política educacional, Santarém torna-se um caso diferenciado por ser um município que se desenvolveu em meio a floresta amazônica - bioma reconhecido como patrimônio da humanidade -, localizado em região hídrica abundante, com grande concentração populacional (aproximadamente 300 mil habitantes). Ademais, a cidade é protagonista de um processo histórico que sempre fez com que cumprisse algum papel de destaque nos ciclos de desenvolvimento econômico mas que configura entre as cidades com os piores índices sociais ainda nos dias atuais, embora tenha localização estratégica nos fluxos e fixos da região amazônica, o que nos dá melhores condições de problematizar porque a política educacional deve considerar outros aspectos que não só o educacional numa perspectiva de sustentabilidade socioambiental.

Sendo assim, o texto está organizado de forma a apresentar Santarém e os aspectos socioeconômico, educacional e ambiental da cidade, finalizando com o desafio de pensar políticas educacionais a partir do cenário que se apresenta.

\section{Uma boneca Russa: Amazônia, Pará, Região de Integração do Baixo Amazonas e, finalmente, Santarém}

Figura 1: Estado do Pará

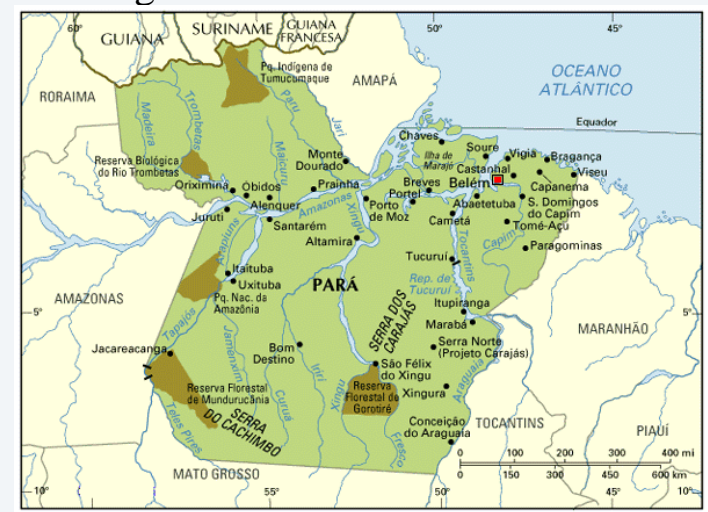

Fonte: IBGE, Mapas/2017 
Para conhecer a região da qual estamos falando é preciso compreender a relação que o município de Santarém guarda com outros recortes territoriais, pois está localizado na Amazônia, no estado do Pará, concentrado na Região de Integração do Baixo Amazonas.

A Amazônia Brasileira contém parte da floresta amazônica e corresponde a $64 \%$ do território brasileiro e envolve nove estados: Acre, Amapá, Amazonas, Pará, Mato Grosso, Rondônia, Roraima, Tocantins e parte do estado do Maranhão. Estes estados destacam-se no âmbito econômico pelo extrativismo vegetal e mineral, agricultura, pesca, indústria (especialmente na Zona Franca de Manaus), comércio e serviços (nas cidades de porte médio e capitais dos estados). De acordo com o Instituto Brasileiro de Geografia e Estatística (IBGE, 2010), no âmbito do agronegócio, possui 39\% do rebanho bovino nacional, produz 37\% da soja colhida no Brasil e responde por $36 \%$ das exportações nacionais, bem como por $40 \%$ da produção de cacau no país, sendo a maior produtora de dendê com $85 \%$ da produção brasileira.

No que se refere à mineração, ela responde por $36 \%$ da quantidade de minério exportada pelo Brasil e participa com 30\% do quantitativo exportado de minério de ferro, já que tem a maior mina de ferro do mundo na Serra dos Carajás, e é grande produtora de cobre, zinco, níquel, bauxita, ouro, estanho, entre outros (IBGE, 2010). A região também se constitui num importante pólo gerador de energia do país. Atualmente produz $16 \%$ e concentra $90 \%$ do potencial hidrelétrico previsto com a expansão do setor até 2024, de forma que possui 22 usinas hidrelétricas planejadas no Plano Decenal de Energia (BRASIL, 2015).

Neste contexto encontra-se o estado do Pará, o qual possui uma extensão territorial de 1.247.954,320 km², uma população estimada em 2015 de 8.175 .113 milhões de habitantes e densidade demográfica de 6,07 hab./ $\mathrm{km}^{2}$ (IPEA, 2017). Os principais segmentos econômicos no estado estão nas áreas de serviços e comércio, setores esses responsáveis pela grande parcela do PIB, muito impulsionada pelo turismo no estado. A agricultura baseia-se no cultivo de laranja, banana, cana-de-açúcar, coco, arroz, mandioca, cacau, feijão e, principalmente, pimenta-do-reino. A pecuária tem grande desenvolvimento na região sudoeste do estado, o rebanho bovino é em torno de 14 milhões de cabeças de gado, além da criação de aves, suínos, equinos e bubalinos. A indústria se concentra na Região Metropolitana de Belém, destacando-se os segmentos madeireiros, alimentícios, químico e alumínio. O extrativismo mineral é umas das principais atividades econômicas do estado com a exploração de bauxita, alumínio, ferro, manganês, calcário, ouro e estanho. No extrativismo vegetal se destacam a madeira e a castanha-do-pará (IPEA, 2017). 
A Região de Integração Baixo Amazonas abrange a Região Noroeste do estado do Pará, entrecortada pelos rios Amazonas e Tapajós e rodovias BR-163 (Rodovia Cuiabá-Santarém), PA254 e PA-419. Abrange uma área de $315.857 \mathrm{~km}^{2}$, correspondendo a 25,32\% do território paraense. Além disso, possui o total de $229.510,50 \mathrm{~km}^{2}$ de seu território constituído por áreas protegidas, o que representa $72,66 \%$ do seu território. Ela é composta pelos municípios de Alenquer, Almeirim, Belterra, Curuá, Faro, Juruti, Monte Alegre, Óbidos, Oriximiná, Prainha, Terra Santa e Santarém. A sua população é de 678.543 mil habitantes, ou 9\% da população do estado, em 2010. Ao longo das últimas décadas essa população vem se concentrando em áreas urbanas, superando a rural a partir da década de 1990, chegando a 60\% do total da população da região. As dinâmicas socioespaciais dessa região se caracterizam por forte vínculo com os rios, sua economia vincula-se à produção de grãos, exploração florestal, agricultura familiar, pesca e empreendimentos mineradores, correspondendo a quarta maior participação $(7,24 \%)$ no PIB estadual (IDESP, 2011).

$\mathrm{Na}$ referida região é que se encontra o município de Santarém. Na sua hidrografia, o principal rio é o Tapajós, que o atravessa no sentido Sul-Norte em seu baixo curso e aloca, na sua foz, pela margem direita, a sede municipal. A rede hidrográfica do município é constituída por seis bacias hidrográficas com destaque para as bacias do rio Amazonas e do Tapajós, importantes para navegabilidade e atividades pesqueiras, além das bacias dos rios Arapiuns, Moju e Mojuí e CuruáUma (IDESP, 2011; IBGE 2010).

Como unidade de conservação sob jurisdição legal, o município contém uma pequena parte da área indígena Arara e a Floresta Nacional do Tapajós, com 600.000 ha $\left(6.000 \mathrm{~km}^{2}\right)$ (IBGE 2007).

Durante o Período Colonial, a Amazônia sofreu sucessivas ameaças de invasão do seu território pelos holandeses, franceses e ingleses, que vinham em busca das riquezas da região. E foi, acima de tudo, a presença desses povos estrangeiros no estuário do rio Amazonas que apressou a colonização portuguesa naquela área. Considera-se que a chegada dos portugueses na região de Santarém ocorreu cento e vinte e seis anos após a chegada ao Brasil em 1500, e fundaram a vila Tapajós, na região habitada por índios Tapaiuçus. A partir de 14 de março de 1758, a vila passou a se chamar Santarém, seguindo orientações do governo português de substituir as denominações indígenas por topônimos de Portugal. Em 1848, a Vila de Santarém foi elevada à categoria de cidade e a partir de 1948, os prefeitos passaram a ser eleitos diretamente pelo voto, até 1969, quando ocorreu a Interventoria Federal em plena vigência do Ato Institucional 
$\mathrm{n}^{\circ} 5$ do governo militar. Assim, Santarém passou à condição de município de Área de Segurança Nacional, até 1985, com o fim da ditadura militar (SANTARÉM, 2017).

A zona rural do município é grande e é composta de forma predominante por pequenos produtores que praticam a agricultura de subsistência, tendo como principais cultivos o feijão, a mandioca, o arroz e o milho, associados com a extração do açaí, e algumas árvores frutíferas. Importante destacar também, que a zona rural abarca não só situações do campo enquanto local de produção agrícola e pecuária, mas também situações peculiares à região amazônica, com destaque para aquelas referentes às comunidades de beiras de rio - ribeirinhas - e nativas com raízes indígenas (TRINDADE JR., 2013).

\section{Dimensão socioeconômica}

Com o objetivo de apresentarmos uma fotografia da situação socioeconômica de Santarém, utilizaremos de dados e indicadores demográficos, de oferta de serviços sociais e das condições sociais da população do município oriundas de fontes como IBGE, Instituto de Pesquisa Econômica Aplicada (IPEA), Instituto de Desenvolvimento Econômico Social e Ambiental do Pará (IDESP) e Fundação Amazônia de Amparo a Estudos e Pesquisas (FAPESPA). Quando possível será feita uma comparação com os indicadores do estado do Pará e do Brasil e para alguns indicadores serão utilizadas informações apenas do Pará pela indisponibilidade para o município.

O estudo, como veremos, evidencia as desigualdades sociais, especialmente as vividas pela população parda, negra e habitantes da zona rural.

A população de Santarém era de 294.580 habitantes, sendo 73\% urbana, em 2010, e a população do Brasil era de 190.755.799, sendo 84\% urbana. Santarém era o terceiro maior município dos cento e quarenta e quatro do estado do Pará. Em comparação com outros municípios do país, ele ficava na posição 83 dentre 5570. Sua densidade demográfica é de 12,87 habitantes por km2, colocando-o na posição 62 no estado e na posição 4005 no país. A população do município no ano de 2010 era majoritariamente parda (73\%), seguida de brancos (20\%), pretos (5\%), amarelos (1\%) e indígenas (1\%); diferentemente do país, já que a população se distribuía da seguinte forma: $48 \%$ brancos, $43 \%$ pardos, $7,5 \%$ pretos, $1 \%$ amarelos e $0,5 \%$ indígenas.

Santarém foi historicamente uma cidade com população expressiva por ser um polo localizado no encontro dos dois principais rios de transporte. 
Como veremos, os indicadores apontam de um lado, para essa busca de Santarém como um grande centro de atração da dinâmica populacional e, de outro lado, uma cidade marcada pela desigualdade social, oferecendo condições de vida precária, especialmente nas regiões periféricas da cidade e na região de campo - planalto e rios - desprovidas de infraestrutura e serviços essenciais; o que tem resultado, consequentemente, em problemas sociais, como aumento da criminalidade, e problemas ambientais.

Os setores primário e terciário sustentam a dinâmica econômica de Santarém, contribuindo para o crescimento do PIB. A economia do município depende basicamente das atividades extrativistas, com predominância da exploração da madeira e da pesca. Contudo, nas últimas décadas do século XX, o papel da Amazônia como a nova fronteira agrícola e ou econômica, se vivencia enquanto uma nova realidade econômica atrelada à produção de soja no município e no estado de Mato Grosso. Mas a atividade comercial é a que se destaca absorvendo cerca de $30 \%$ da mão de obra economicamente ativa.

Santarém é também o segundo porto mais importante na Amazônia em embarque de madeira para exportação, estimulada pela implantação do Distrito Florestal Sustentável (DFS) da BR-163, o primeiro do Brasil. Também a empresa Cargill instalou aí um terminal graneleiro.

O PIB per capita deflacionado para o município, em 2014, era de $\mathrm{R} \$ 13.043,21$. O do Pará era de R\$13.775,00 e para o Brasil, R\$24.626,00. Na comparação com os demais municípios do estado, sua posição era de 34 entre 144. Já na comparação com cidades do Brasil todo, sua colocação era de 2933 entre 5570.

A desigualdade de renda no município, aferida pelo índice de Gini, era 0,56, em 1991, 0,61, em 2000 e 0,59 em 2010. Para o ano de 2010, o do Pará era 0,63 e o do Brasil 0,61. O rendimento médio mensal domiciliar per capita nominal era de $\mathrm{R} \$ 354,00$, do Pará $\mathrm{R} \$ 429,00$ e do Brasil, R\$ 767,02, também em 2010. Havia, contudo, uma imensa desigualdade entre as zonas urbanas, com rendimento de $\mathrm{R} \$ 418,00$, e a zona rural, $\mathrm{R} \$ 168,00$.

O (IDHM) de Santarém era de 0,691, em 2010, o que situa esse município na faixa de Desenvolvimento Humano Médio (IDHM entre 0,600 e 0,699). A dimensão que mais contribui para o IDHM do município é Longevidade, com índice de 0,807, seguida de Educação, com índice de 0,648, e de Renda, com índice de 0,632.

Entre 2000 e 2010 o IDHM passou de 0,555 em 2000 para 0,691 em 2010 uma taxa de crescimento de $24,50 \%$. O hiato de desenvolvimento humano, ou seja, a distância entre o IDHM do município e o limite máximo do índice, que é 1, foi reduzido em 69,44\% entre 2000 e 2010 . No 
município, a dimensão cujo índice mais cresceu em termos absolutos foi Educação (com crescimento de 0,426), seguida por Longevidade e por Renda.

A porcentagem de pobres era de 22,17 no Pará e 11,50 no Brasil, em 2014. A proporção de pessoas pobres, ou seja, com renda domiciliar per capita inferior a $\mathrm{R} \$ 140,00$ (a preços de agosto de 2010), passou de 59,50\%, em 1991, para 49,55\%, em 2000, e para 31,07\%, em 2010, respectivamente.

Em 2015, o salário médio mensal era de 2.1 salários mínimos. Considerando domicílios com rendimentos mensais de até meio salário mínimo por pessoa, tinha $45.6 \%$ da população nessas condições, o que o colocava na posição 111 de 144 dentre as cidades do estado e na posição 2078 de 5570 dentre as cidades do Brasil.

O trabalho infantil atingia $12,4 \%$ das crianças e adolescentes de 10 a 17 anos do município, e desses, 60\% eram do sexo feminino, em 2010. De 10 a 13 anos 7\% trabalhavam, sendo 63\% na zona rural; de 14 ou 15 anos - 12\% e 56\% rural; e 16 ou 17 anos - 22\% trabalhavam sendo $46 \%$ rural.

Em termos de moradia, a proporção de pessoas vivendo em domicílios improvisados no Pará era de 30\% e no Brasil 17\%, em 2013. No Pará, acessos adequados a abastecimento de água estão aquém da média nacional. Além disso, as disparidades entre as áreas rurais e urbanas revelam desigualdades ainda preocupantes. A ausência deste serviço implica diretamente na qualidade de vida da população, ocasionando diversas doenças de veiculação hídrica. Este indicador é importante para a caracterização básica da qualidade de vida.

A água encanada no Brasil aumentou sua cobertura, passando de 83,3\%, em 2004, para 87,7\%, em 2009. As diferenças regionais, apesar de diminuírem nesse período, ainda são elevadas e, notadamente no caso do Pará, cerca de $48 \%$ de sua população continuavam sem esse atendimento em 2009. Esse baixo valor médio se deve basicamente à zona rural, onde o percentual de cobertura era de 44,2\% em 2009.

$\mathrm{Na}$ cidade, domicílios com acesso à rede geral de água eram na ordem de 60\%, 20\% de poço e $21 \%$ de outra fonte (6\% rio, açude, igarapé), em 2010. Na zona rural, apenas $27 \%$ dos domicílios eram atendidos por rede geral de abastecimento de água. A ausência de esgotamento sanitário ou mesmo o fornecimento do serviço de maneira ineficiente é fator que contribui para o aumento nos níveis de poluentes e podem acarretar a depreciação da qualidade da água e a perda da capacidade de sustentabilidade do ecossistema, com consequente aumento do nível de toxicidade e deterioração da saúde humana. 
Dos domicílios com acesso ao sistema de esgoto, apenas $2 \%$ estavam conectados à rede geral, em Santarém em 2010, 38\% possuíam fossa séptica e 59\% outras formas consideradas precárias. No Pará, $10 \%$ à rede geral e $86 \%$ eram atendidos por outra forma. No Brasil, 55\% eram conectados à rede geral e $42 \%$ por outra forma.

O acesso dos domicílios de Santarém à energia elétrica era de $99 \%$ e na zona rural 69\%; enquanto para o Pará era 95\% e $81 \%$ e para o Brasil 99\% e 93\%, respectivamente. No que tange a outros conjuntos de serviços e bens disponíveis aos domicílios do município nas zonas urbana e rural, podemos destacar com base em dados de 2010: a coleta de lixo na zona urbana 76\%, (queimado 5\%, jogado na rua ou rio $10 \%$ e enterrado 9\%) e na zona rural 18\%; geladeira $81 \%$ e $40 \%$; rádio $70 \%$ e $69 \%$; televisão $86 \%$ e $54 \%$; microcomputador $20 \%$ e $3 \%$; microcomputador com acesso à internet $12 \%$ e $1 \%$; automóvel $18 \%$ e $4 \%$; motocicleta $19 \%$ e $14 \%$; telefone fixo $19 \%$ e $3 \%$ e celular $74 \%$ e $35 \%$.

Destaque-se que o acesso a telefone celular no Brasil encontra-se em plena ascensão. Em 2001, a posse de celular, por pelo menos um morador do domicílio, atingia a cifra de $31 \%$. Esta cobertura subiu para 81,1\%, em 2009. As trajetórias do Norte e do Pará seguem de perto a nacional, chegando, em 2009, às coberturas de 73,9\% e 73,1\%, respectivamente.

Com relação ao acesso à internet, pode-se afirmar que esse item ainda é restrito a uma parcela menor da população, mesmo em nível nacional, pois apenas $42 \%$ da população brasileira o possuíam em 2014. Apesar do aumento do seu acesso nos últimos anos, a população rural encontrava-se praticamente alijada desse processo. As diferenças regionais eram intensas e, no Pará, a taxa de acesso a internet no domicílio era de 17\% para a população urbana e para a rural o acesso era praticamente insignificante $(2,2 \%)$.

Desde a redemocratização do Brasil, com a promulgação da Constituição de 1988, a região norte do país tem sido alvo de diversos programas de desenvolvimento econômico como Fundo Nacional de Financiamento do Norte (FNO), Plano Nacional de Fortalecimento da Agricultura Familiar (Pronaf), Plano Nacional de Qualificação (PNQ), Plano Territorial de Qualificação (Planteq), entre outros - cujo foco é a qualificação da mão de obra e a produção em média e pequena escala, o que justifica o $5^{\circ}$ maior Índice de Qualificação da Mão de Obra (IQM) e o $8^{\circ}$ maior Índice de Produto Municipal (IPM) do Pará. Soma-se a isso o fato de o município ter participado de forma especial dos ciclos econômicos desde o final do século XIX, acumulando alguma experiência que também permitisse, 100 anos depois, algum tipo de destaque.

Ao compararmos Santarém com a situação estadual, está sempre entre os $50 \%$ primeiros, o que corrobora com os índices Fapespa, mas em termos nacionais, ocupa majoritariamente o 
grupo da segunda metade. Tal situação pode desvelar a precariedade da conjuntura municipal no estado. Ora, se uma das mãos de obra mais qualificada do Pará é pobre, parda, com saúde precária, moradias inadequadas em aglomerados subnormais, sem acesso a internet, com baixa cobertura de água encanada e esgoto, convivendo com taxas preocupantes de Índice Parasitário de Malária, homicídio e trabalho infantil, estamos diante de um trabalhador explorado, que beira a escravidão. Essa situação justifica a mesma cidade ter o $39^{\circ}$ maior índice de Renda Média e o $49^{\circ}$ de Segurança.

Não podemos ignorar que o município avançou em diversas frentes no final do século XX e início do século XXI, entretanto, tais avanços foram insuficientes para superar a segregação social, uma vez que o desenvolvimento econômico, em termos totais, destaca-se fortemente frente ao desenvolvimento social. Para este contexto também devemos considerar políticas que vincularam aspectos socioeconômicos com educacionais, a exemplo do Bolsa Família, Programa de Erradicação do Trabalho Infantil (Peti) e Lei de Assistência Social, mas mesmo intercalando setores distintos, não sobrepuseram o cenário socioeconômico alarmante da cidade.

\section{Dimensão educacional}

Observando-se a questão do analfabetismo de pessoas com 15 anos ou mais, Santarém apresentou uma redução de 11,7\% em 2000 para 7,4\% em 2010, que colocou o município na posição 139 dentre os 144 municípios do Pará e na posição 4380 do país. A situação se torna mais grave quando se focalizam os índices referentes às populações rurais do estado. Ainda que as tendências de queda tenham sido mais intensas nessas zonas, os patamares continuaram alarmantes, com taxa por volta de $20 \%$. Na faixa de 60 anos ou mais, $25 \%$ nunca frequentaram escola.

A proporção de crianças de 0 a 5 anos de idade com responsável ou cônjuge analfabeto era de $12 \%$. O Pará tem escolaridade, medida pela média de anos de estudo da população de 15 anos ou mais, menor do que a nacional em 2009. No estado, essas médias eram de 5,9 e 6,7 anos de estudo, enquanto, para o país, de 6,8 e 7,5 anos, respectivamente. A população rural do Pará encontrava-se ainda, em 2009, com escolaridade baixa: 4,8 anos de estudo.

No município de Santarém, das pessoas de 10 anos ou mais, 50\% não tinham instrução ou tinham o ensino fundamental incompleto; $21 \%$ o ensino fundamental completo e ensino médio incompleto; $24 \%$ tinham o ensino médio completo e o ensino superior incompleto e, finalmente, $5 \%$ possuíam o ensino superior completo, em 2010. 
Com relação à taxa de escolarização, os dados apontavam que no mesmo ano, havia um baixo atendimento das crianças na faixa etária de 0 a 3 anos, pois apenas $10 \%$ delas frequentavam creche, entretanto esta faixa não está contemplada como idade escolar obrigatória, embora a demanda seja bastante alta justificada por mães, pais ou responsáveis pela necessidade de terem um local para deixar seus filhos/tutelados enquanto trabalham (ASSIS, 2017); já o atendimento da faixa de 4 a 5 anos, a primeira faixa obrigatória, era melhor (71\%), mas mesmo assim cerca de um terço delas não tinham acesso à pré-escola.

A taxa de escolarização (para pessoas de 6 a 14 anos) foi de 97.3\% em 2010. Isso posicionava o município em $24^{\circ}$ de 144 dentre as cidades do estado e na posição 3221 de 5570 dentre as cidades do Brasil. No que se refere às crianças de 6 anos, 7 a 9 e 10 a 14, pode-se dizer que o atendimento estava praticamente universalizado, uma vez que $95 \%$ das crianças, $98 \%$ e $97 \%$, respectivamente, frequentavam o ensino fundamental. Tal universalização deu-se devido a meta atingida do PNE de 2001.

Na faixa de 15 a 19 anos, $71 \%$ frequentavam escola; de 20 a 24 anos, $26 \%$ e de 25 a 29 anos, $14 \%$. De 30 a 59 anos $7 \%$ frequentavam escola e de 60 anos ou mais apenas $1 \%$ frequentava. $7 \%$ das crianças e adolescentes de 10 a 17 anos não frequentavam a escola e desses, 83\% eram pardos ou pretos.

Proporções de crianças e jovens frequentando ou tendo completado determinados ciclos indica a situação da educação entre a população em idade escolar do estado. No município, a proporção de crianças de 5 a 6 anos na escola é de 89,16\%, em 2010. A proporção de jovens de 15 a 17 anos com ensino fundamental completo é de 60,20\%; e a proporção de jovens de 18 a 20 anos com ensino médio completo é de 37,61\%. Entre 1991 e 2010, essas proporções aumentaram, respectivamente, em 54,25 pontos percentuais, 63,72 pontos percentuais, 45,36 pontos percentuais e 31,00 pontos percentuais (PNUD).

O indicador população de 18 anos ou mais com o ensino fundamental completo, carrega uma grande inércia, em função do peso das gerações mais antigas, de menor escolaridade. Entre 2000 e 2010 , esse percentual passou de $39,26 \%$ para $56,86 \%$, no município, e de $39,76 \%$ para 54,92\%, no Pará. Em 1991, os percentuais eram de 25,76\%, no município, e 30,09\%, no estado. Em 2010, considerando-se a população municipal de 25 anos ou mais de idade, 10\% eram analfabetos, $51 \%$ tinham o ensino fundamental completo, $34 \%$ possuíam o ensino médio completo e $7 \%$, o superior completo. No Brasil, esses percentuais eram, respectivamente, $12 \%, 51 \%, 36 \%$ e $11 \%$. 
Das 108.044 pessoas de Santarém que frequentavam escola, em 2010, estavam matriculadas:

Quadro 1: Distribuição percentual da matrícula por tipo de escola - 2015

\begin{tabular}{|l|c|c|}
\cline { 2 - 3 } \multicolumn{1}{l|}{} & $\begin{array}{c}\text { Escolas } \\
\text { Públicas }\end{array}$ & $\begin{array}{c}\text { Escolas } \\
\text { Privadas }\end{array}$ \\
\hline $\begin{array}{l}\text { (0 a } 3 \text { anos) } \\
\text { Pré - escola } \\
\text { (4 a 5 anos) }\end{array}$ & 74 & 26 \\
\hline $\begin{array}{l}\text { Classe de Alfabetização } \\
\text { (mais de 7 anos que não sabem ler/escrever)* }\end{array}$ & 70 & 30 \\
\hline $\begin{array}{l}\text { Alfabetização de Jovens e Adultos } \\
\text { (acima de 16 anos sem saber ler e escrever) }\end{array}$ & 73 & 27 \\
\hline $\begin{array}{l}\text { Ensino Fundamental } \\
\text { (6 a 14 anos) }\end{array}$ & 100 & 0 \\
\hline $\begin{array}{l}\text { Educação de Jovens e Adultos no Ensino Fundamental } \\
\text { (acima de 16 anos sabendo apenas ler e escrever) }\end{array}$ & 97 & 3 \\
\hline $\begin{array}{l}\text { Ensino Médio } \\
\text { (15 a 17 anos) }\end{array}$ & 93 & 7 \\
\hline $\begin{array}{l}\text { Educação de Jovens e Adultos no Ensino Médio } \\
\text { (acima de 18 anos com Ensino Fundamental Completo) }\end{array}$ & 93 & 7 \\
\hline Educação Superior & 25 & 75 \\
\hline Especialização & 18 & 82 \\
\hline Mestrado & 51 & 49 \\
\hline Doutorado & 100 & 0 \\
\hline "em extinço
\end{tabular}

*em extinção

Fonte: Realizado pelos autores com dados do IBGE

A proporção de matrículas nos níveis educacionais na zona rural em relação ao total, em 2015: Creche 5\%; Pré-escola 35\%; Ensino fundamental - anos iniciais 36\%; Ensino fundamental anos finais 32\%; Ensino médio 2\%; Educação profissional 7\%; Educação de jovens e adultos 13\%; Educação especial 33\%. Já a proporção de matrículas em tempo integral é de $32 \%$ no Ensino fundamental e 1\% no Ensino Médio.

Em 2017, a Secretaria Municipal da Educação, atendia 33.686 alunos em 58 escolas urbanas, 10.302 alunos em 91 escolas do campo, no planalto, e 15.844, em 233 escolas do campo, na região dos rios. $70 \%$ dessas escolas eram multisseriadas.

Quanto aos indicadores de desempenho, observa-se que o desempenho das escolas estaduais é pior que o das escolas municipais e particulares; cabe ressaltar o alarmante desempenho das escolas estaduais do ensino médio com uma taxa de fracasso próxima de $26 \%$, conforme dados do Quadro 2. 
Quadro 2: Taxa de desempenho por dependência administrativa - 2015.

\begin{tabular}{|c|c|c|c|c|c|}
\cline { 2 - 6 } \multicolumn{1}{c|}{} & \multicolumn{3}{c|}{ Ensino Fundamental } & \multicolumn{2}{c|}{ Ensino Médio } \\
\cline { 2 - 6 } \multicolumn{1}{c|}{} & Estadual & Municipal & Particular & Estadual & Particular \\
\hline Aprovado & 77 & 93 & 98 & 74 & 92 \\
\hline Reprovado & 14 & 6 & 1 & 8 & 92 \\
\hline Evadido & 8 & 0,5 & 0,2 & 18 & 5 \\
\hline
\end{tabular}

Fonte: Realizado pelos autores com dados MEC/INEP

Quanto a indicadores de infraestrutura física, o Quadro 3 apresenta o número de escolas no município de Santarém, destacou-se o grande o número de escolas municipais.

Quadro 3: Distribuição percentual de número de escolas por dependência administrativa - 2015.

\begin{tabular}{|c|c|c|c|c|}
\cline { 2 - 5 } \multicolumn{1}{c|}{} & Estadual & Municipal & Particular & Total \\
\hline Pré - escola & 0 & 285 & 38 & 323 \\
\hline Ensino Fundamental & 26 & 378 & 37 & 441 \\
\hline Ensino Médio & 26 & 0 & 7 & 34 \\
\hline
\end{tabular}

Fonte: Realizado pelos autores com dados MEC/INEP

Desse expressivo número de escolas da rede pública municipal de Santarém, 57,6\% são constituídas por apenas uma sala de aula. Essa realidade se concentra mais nas escolas da zona rural, que são inadequadas para uma aprendizagem de qualidade, considerando seus equipamentos, infraestrutura e instalações sanitárias (COLARES, 2016).

Quadro 4: Número e proporção de escolar públicas por zona urbana e rural - 2015

\begin{tabular}{|c|c|c|c|c|}
\cline { 2 - 5 } \multicolumn{1}{c|}{} & \multicolumn{2}{c|}{ Urbana } & \multicolumn{2}{c|}{ Rural } \\
\hline Creche & 19 & $83 \%$ & 4 & $17 \%$ \\
\hline Pré-escola & 69 & $12 \%$ & 216 & $88 \%$ \\
\hline Ensino Fundamental & 85 & $21 / \%$ & 319 & $79 \%$ \\
\hline Ensino Médio & 26 & $76 \%$ & 8 & $24 \%$ \\
\hline
\end{tabular}

Fonte: Realizado pelos autores com dados MEC/INEP

Apesar destas concertações permitirem atingir maior número de alunos, acaba trazendo novos desafios ao magistério, que deve considerar, entre outros, o fato da qualificação de professores. Em escolas urbanas, em 2010: com formação de nível ensino médio $21 \%$ e de ensino superior $79 \%$, enquanto que nas escolas rurais era de ensino médio $40 \%$ e ensino superior $60 \%$. Ademais, apenas $41 \%$ dos professores do Estado lecionam disciplinas compatíveis com sua formação no ensino superior.

Da mesma forma que as ações desenvolvimentistas atingiram algum êxito, o mesmo pode ser reconhecido nas políticas educacionais no município de Santarém, entretanto, são ações que também compartilham da ineficiência quando se trata de emancipação social.

No caso da educação, ter atingido a meta do PNE referente à universalização do Ensino Fundamental é fator de alta relevância; podemos dizer que a existência dos programas Bolsa 
Família e Renda Mínima, que vinculam a frequência escolar com a ajuda financeira, foi determinante, pois toca no problema da mão de obra infanto-juvenil. Em outras palavras, a partir do momento em que ir para escola gera uma renda, a família não tem mais a pressão de que aquele membro passe a contribuir com o orçamento mensal.

As políticas que vinculam aspectos econômicos e educacionais tiveram um impacto pontual na população do município, mas nem economicamente, nem socialmente modificaram o cenário de segregação; talvez tenha até contribuído para seu acirramento, vez que dá condições para a formação de mão de obra barata, qualificada e precoce para o tipo de atividade dominante na região que se concentra nos setores primário e terciário.

Preocupante também é a constância histórica do analfabetismo e da evasão escolar a partir dos 15 anos. Nos últimos 50 anos a cidade não conseguiu diminuir, efetivamente, a taxa de analfabetos; bem como não conseguiu reverter a linha crescente de evasão escolar a partir dos 15 anos, ficando as matrículas sempre abaixo dos $40 \%$, ao encontro de uma situação precoce de acesso ao mercado de trabalho, o que se agrava na área rural em que o percentual de matrículas não ultrapassa os $36 \%$ na educação básica - 4 a 17 anos -.

O cenário torna-se ainda mais preocupante ao considerarmos que apenas $1 / 3$ da população frequenta a escola, com grande concentração na educação infantil e ensino fundamental públicos municipais; escolas estas que estão na mesma situação das residências identificadas como aglomerados subnormais, em que a grande maioria trabalha com classes multiseriadas e destas, a metade constitui-se enquanto instituição possuindo apenas uma sala de aula.

No caso de Santarém, esta opção pela flexibilização da organização escolar, embora tenha aumentado o número de matrículas, em especial na zona rural, e tenha demandado de professores, com baixa formação, metodologias diferenciadas para atender as distintas realidades, é o dado mais relevante para reconhecer que há um cenário de emergência educacional, pois não se trata da implementação de uma política educacional com viés pedagógico progressista de atuação que respeite a individualidade dos educandos, mas sim por impossibilidade de implementação da política original.

\section{Dimensão ambiental}

A partir dos anos 70 do século XX, a Amazônia se tornou espaço estratégico no plano nacional de integração territorial, assumindo a condição de fronteira econômica (BECKER, 1990), momento a partir do qual algumas cidades, dentre elas Santarém, tornaram-se referências para programas, projetos e investimentos. 
Neste contexto, nos últimos 30 anos, a Região de Integração Baixo Amazonas experimentou a expansão da pecuária, do extrativismo mineral e florestal, da agricultura mecanizada e tradicional, da atividade industrial e da ocupação urbana que intensificou a degradação do meio ambiente levando ao desmatamento, queimadas, poluição dos rios e perda de biodiversidade. Ficando comprometida a qualidade ambiental e consequentemente as condições de bem-estar da população.

Surge, então, a necessidade de se avaliar a condição do meio ambiente como subsídio à elaboração de políticas públicas, para tanto o governo do estado do Pará montou os Indicadores da Qualidade Ambiental (IQA) para todas as Regiões de Integração, que se agrupam em: áreas protegidas, índice de desmatamento, índice de focos de calor e capacidade institucional.

As áreas protegidas são aquelas que expressam a dimensão, distribuição e extensão dos espaços territoriais que estão legalmente protegidos em relação à região de integração dos municípios que compõem. Para tanto, foi considerada também a área que se refere a Terras Indígenas, que são áreas institucionalmente protegidas.

A Lei $n^{\circ} 9.985$ de 2000, que institui o Sistema Nacional de Unidades de Conservação da Natureza define Unidades de Conservação em seu artigo $2^{\circ}$ inciso I como:

Espaço territorial e seus recursos ambientais, incluindo as águas jurisdicionais, com características naturais relevantes, legalmente instituídos pelo Poder Público, com objetivos de conservação e limites definidos, sob regime especial de administração, ao qual se aplicam garantias adequadas de proteção. (BRASIL, 2000).

Estas estão divididas em dois grupos: a de Proteção Integral (PI) e as de Uso Sustentável (USO). Estas áreas são importantes para a avaliação de indicadores de qualidade ambiental; pois, segundo pesquisas realizadas, as taxas de derrubada da floresta no interior dessas áreas são significativamente menores quando comparadas às suas áreas adjacentes. Atualmente, segundo dados do Macrozoneamento Ecológico Econômico do Pará (SEMA, 2007), 57,52\% do território do estado do Pará são constituídos por áreas protegidas (Terras Indígenas somadas às Unidades de Conservação). Já Região de Integração Baixo Amazonas possui o total de $229.510,50$ km² de seu território constituído por áreas protegidas, o que representa 72,66\% do seu território. O percentual de áreas protegidas em Santarém é de $20 \%$.

O meio ambiente é um importante indicador da identidade da região do Baixo Amazonas. Dentre as atividades de degradação, destaca-se mais aquela relacionada ao problema de alteração de uso do solo para a plantação da soja, criação de gado, principalmente nos municípios de Santarém e Belterra e pela extração de minérios nos municípios de Juruti e Oriximiná. Estas 
atividades têm gerado o desflorestamento com incentivos e financiamentos do Estado, para grandes firmas nacionais e internacionais.

De outro lado, também vem ocorrendo que as populações locais são pressionadas pelos agentes destes negócios, considerados estratégicos à balança do comércio internacional, com efeitos danosos ao meio ambiente. Há uma opção pelos grandes investimentos (minerais, agroextativistas, portos, ferrovias etc.), buscando atender setores que historicamente geraram acumulação de riqueza e concentração de renda. A produção de grãos, particularmente a soja, contribuiu de maneira significativa, juntamente com a exploração mineral (ouro e bauxita), para promover a desapropriação de agricultores familiares, o desmatamento, a exploração de madeira e a contaminação por mercúrio do leito dos rios.

A questão ambiental torna-se um problema se a estratégia for a continuidade dos processos de exploração da natureza a partir de políticas neodesenvolvimentistas e neoindustriais, constituídas de modo exógeno às dinâmicas das populações locais, particularmente com a penetração das grandes plantações de soja, impulsionadas pelas novas fronteiras agrícolas, além da implantação de novos terminais portuários e da exploração mineral.

De acordo com os Indicadores de qualidade ambiental dos municípios da Região de Integração Baixo Amazonas do Instituto de Desenvolvimento Econômico Social e Ambiental do Pará - IDESP o índice de desmatamento é aquele que

[...] expressa a perda da cobertura florestal primária no território, considerando a relação entre o desflorestamento anual e as áreas dos municípios paraenses. A retirada da cobertura vegetal original gera consequências como perda de biodiversidade, degradação do solo, erosão, alteração nos cursos d'água e contribui para as mudanças climáticas. (IDESP, 2013 p.31).

Tendo essa definição em mente, a Região de Integração Baixo Amazonas possuía um total de $19.732 \mathrm{~km}^{2}$ de área desmatada de 2001 até 2011, correspondendo a 6,25\% do seu território. Da série histórica de desmatamento, para os municípios da região o município que liderou o desmatamento, com relação aos dados de incremento, foi Santarém.

No que tange ao índice de focos de calor, que são as queimadas e os incêndios florestais, estes são detectados por satélites de monitoramento de focos de calor na superfície terrestre (IDESP, 2013); no Pará, como no Brasil, o uso do fogo é uma das práticas para renovação de pastagens e liberação de novas áreas para as atividades agropecuárias. Os incêndios florestais, por sua vez, correspondem a situações de fogo, originado a partir do seu uso não autorizado para fins agropastoris, consumindo grandes áreas com vegetação (nativa ou não), pastagens e cultivos, resultando em queimadas descontroladas. Tanto as queimadas, quanto os incêndios florestais 
destroem, anualmente, grandes áreas florestais no Pará, sendo uma ameaça aos ecossistemas locais. Na Região de Integração Baixo Amazonas, os focos de queimadas tiveram um aumento de $25,16 \%$ se comparado o total de focos de 2006 com o ano de 2012, quando foram identificados 2.900 focos na região. Em Santarém foram: 385 em 2006, 161 em 2007, 268 em 2008, 783 em 2009, 344 em 2010, 430 em 2011, 487 em 2012.

Por fim, a capacidade institucional é aferida pela existência de órgão gestor e conselho municipal de meio ambiente. Apenas os municípios de Alenquer, Almeirim, Prainha, Curuá, Santarém e Juruti possuíam, em 2015, uma secretaria de meio ambiente com infraestrutura de gestão ambiental do município, dentre os onze municípios da Região de Integração Baixo Amazonas. Em relação ao quadro funcional, segundo informações disponibilizadas pelo IBGE, referentes ao ano de 2008, a Região de Integração Baixo Amazonas apresentava o total de 81 pessoas trabalhando na área ambiental. Santarém era o município que possuía o maior número de agentes ambientais: 25 funcionários.

De acordo com o Portal do Encontro Nacional de Comitês de Bacias Hidrográficas, existente devido ao Plano Nacional de Recursos Hídricos, toda a região amazônica possui apenas 3 comitês. Nenhum deles localizado no Pará, embora a Região de Integração Baixo Amazonas esteja vinculada ao Comitê de Bacia Hidrográfica Tapajós Amazonas (CBH - TAPAM), contando com 4 membros; o que nos parece inviabilizar qualquer plano que venha a considerar a bacia hidrográfica, lida enquanto bacia ambiental, como unidade de planejamento intersetorial.

Quanto à existência de conselho municipal de meio ambiente, a maioria dos municípios não apresentava este órgão em sua estrutura administrativa; fato que compromete a participação da comunidade nas discussões ambientais junto ao poder público. Os municípios Belterra, Santarém, Alenquer e Óbidos possuíam o Conselho com caráter consultivo e deliberativo.

Ao que tudo indica, alguns instrumentos de gestão importantes ainda são inexistentes na região, como Planos Diretores Municipais, Planos de Gestão de Recursos Hídricos do Baixo Tapajós e Baixo Xingu, Plano de Gestão Ambiental Rural, Implementação do Programa de Formalização e Desenvolvimento Sustentável da Pequena Mineração, bem como a criação e implantação de Reservas Extrativistas (RESEX) e Reservas de Desenvolvimento Sustentável (RDS).

O cenário dos aspectos de sustentabilidade apenas confirma o que já foi destacado: se o desenvolvimento econômico total expandiu em detrimento do desenvolvimento socioeconômico e educacional da população, com ele também se ampliou a exploração descompromissada do bioma amazônico. 
Mesmo sendo formado por boa parte de área protegida, nos últimos dez anos, Santarém liderou o desmatamento, o aumento de queimadas, a desapropriação de terras para agricultura familiar e a alteração de uso do solo para plantio de grãos na região. Situação que parece contraditória se, no estado, é uma das poucas cidades que possuem secretaria e conselho municipal de meio ambiente; contudo, se a política regional e nacional é de exploração de matéria prima, sem ênfase nos critérios de sustentabilidade, a existência destes aparatos sociais talvez contribua com a institucionalização de ações de degradação em lugar de combate-las.

É de se reconhecer que o município possui condições naturais favoráveis ao desenvolvimento sustentável, e mesmo que muitas ferramentas para uma gestão deste tipo ainda sejam carentes, outras tantas já estão disponíveis para que valorize, em primeiro lugar, a sustentabilidade, que garantirá desenvolvimento, não só econômico, mas social. Desta forma, o município poderá reverter sua situação social potencialmente insustentável e evitar a piora de uma situação intermediária do meio ambiente, que se garante apenas pela peculiaridade da alta concentração florestal da Amazônia.

\section{Considerações Finais}

Uma população vivendo em uma situação de vulnerabilidade social não tem condições de romper com o ciclo de segregação social, e embora reconheça a importância de sua cultura e sua terra, não tem condições de dar-lhe a devida atenção porque lhe falta as condições mínimas necessárias à sobrevivência. Trata-se de um contexto em que tanto a floresta quanto os seres humanos buscam sobreviver frente à exploração desenvolvimentista.

Nesse sentido, considerando que o PNRH nos permite planejar a partir da bacia ambiental; que a análise do urbano na Amazônia demanda novos conteúdos metodológicos; e que Santarém tem um papel diferenciado nas relações no espaço regional, uma política educacional que articule os aspectos socioeconômicos (dimensão social), educacionais (dimensão política) e de sustentabilidade (dimensão espacial), envolvendo as esferas municipal, estadual e federal, é, não só urgente, mas necessária.

A relação feita entre o PNE e os programas Bolsa Família e Renda Mínima nos dão indicativos de que, se a política pública for ampla, abarcando as complexidades da localidade a qual se destina, sem focar uma determinada população, terá êxito; pois a universalização do ensino fundamental, com queda na mão de obra infantil até 14 anos ocorreu, mas caracterizou-se como um hiato frente ao cenário de segregação da cidade, tornando-se insuficiente. 
Além disso é preciso reconhecer que, por se tratar da Amazônia, as definições rural e urbana de um espaço geográfico são insuficientes, demandando a compreensão de uma "cidade da floresta" e não "na floresta" (TRINDADE JR., 2013)

Postas estas condições de uma política que tenha como objetivo sobrepor a segregação escolar, voltemos ao objetivo 4 da Agenda 2030: “Assegurar a educação inclusiva e equitativa e de qualidade, e promover oportunidades de aprendizagem ao longo da vida para todos", para identificar que, apesar de colocar em destaque a educação, depende de ações convergentes que vem antes, durante e depois dele.

Assegurar algo para gerações futuras, requer garantir a mesma coisa para as gerações presentes, e esta garantia depende de um terreno apropriado para que se consolide. Em outras palavras, pensar a permanência, requer pensar o acesso, não um acesso imediatista que guarde relação apenas com a ida à instituição escolar e a vaga, mas com tudo que as antecede, como saúde, alimentação, higiene, moradia adequada, respeito à cultura de origem e a tantos outros direitos já conquistados. O diagnóstico a partir dos indicadores socioeconômicos e ambientais seria o primeiro passo, pois subsidiaria a concertação da política articulada para a cidade da floresta a fim de garantir o acesso à educação de forma igualitária e equitativa.

Outra situação é a permanência, com vistas a uma educação inclusiva, equitativa e de qualidade, cujos indicadores educacionais ajudam a pensar a estrutura e organização escolares, mas que também dependem de indicadores pedagógicos a fim de problematizar as avaliações, inclusive as de larga escala. É cogitar como materializar o que se entende por uma educação de qualidade.

Finalmente, a situação de continuidade, para promover oportunidades de aprendizagem ao longo da vida para todos. A educação não acontece só no espaço escolar, tampouco vincula-se a uma trajetória acadêmica; e se está relacionada a um desenvolvimento sustentável, deverá considerar suas muitas faces, para as mais diversas situações, o que se garante não só com o fortalecimento do acesso e da permanência, mas em especial admitindo os sujeitos enquanto agentes de transformação, pois serão os melhores multiplicadores, avaliadores e promotores desta política.

Para tanto, é preciso romper com a ideia de etapas, já que a universalidade da política atenderá diferentes pessoas em diferentes situações; mas que nem por isso, tornar-se-á uma política impraticável. A política pensará em atacar, simultaneamente, as três frentes: as condições de acesso, as condições de permanência, e as condições de continuidade, e isto, considerando não 
só os sujeitos da política, mas na mesma medida, aqueles que a põe em marcha, como os professores, as escolas, as instâncias públicas, movimentos sociais, entre outros.

Da mesma forma que um mundo globalizado permite que identifiquemos situações e problemas semelhantes ao redor do planeta, também nos dá condições de pensar de forma articulada e global, reunindo todo tipo de profissionais para elaborar, implementar, avaliar e dar continuidade a um ciclo de políticas que não sejam mais só sociais, só ambientais ou só educacionais, mas que sejam efetivamente, públicas.

\section{Referências}

ASSIS, Ana Elisa Spaolonzi Queiroz. Creche não é direito público subjetivo: uma questão de política pública ou de interpretação jurídica?. In: COLARES, Maria Lilia Imbiriba Sousa; COSTA, Sinara Almeida da. (Org.). A educação infantil no centro do debate: do direito adquirido às práticas cotidianas desenvolvidas nas creches e pré-escolas. 1ed.Curitiba: CRV, 2017, v. 1, p. 55-73.

BECKER, B. K. Amazônia. São Paulo: Ática, 1990.

BRASIL, Sistema Nacional de Unidades de Conservação da Natureza Lei n. 9.985 de 2000. Disponível em: http://www.planalto.gov.br/ccivil_03/leis/L9985.htm. Acesso em 18 mar. 2017.

BRASIL. Política Nacional de Recursos Hídricos. Lei n. ${ }^{\circ} 9.433$ de 1997. Disponível em: http://www.planalto.gov.br/ccivil_03/leis/L9433.htm. Acesso em 30 mar. 2017.

BRASIL, Plano Decenal de Expansão de Energia 2024. Ministério de Minas e Energia. Empresa de Pesquisa Energética. Brasília: MME/EPE, 2015. Disponível em: http://www.epe.gov.br/PDEE/Relat\%C3\%B3rio\%20Final\%20do\%20PDE\%202024.pdf. Acesso em 30 mar. 2017.

BRITO, Regivane dos Santos; PRADO, Jany Rodrigues; NUNES, Claudio Pinto. As condições de trabalho docente e o pós-estado de bem-estar social. Revista Tempos e Espaços em Educação (online), v. 10, p. 165-174, 2017. Disponível em:

https://seer.ufs.br/index.php/revtee/article/view/6676. Acesso em: 21 ago. 2017.

CALEJON, Laura Marisa Carnielo. Desempenho escolar e vulnerabilidade social. Revista Exitus, v. 1, n. 1, jul./dez. 2011, p. 149-164. ISSN 2237-9460. Disponível em:

http://www.ufopa.edu.br/portaldeperiodicos/index.php/revistaexitus/article/view/214. Acessado em: 17 abr. 2017.

CASTRO NETA, Abília Ana de; CARDOSO, Berta Leni Costa, NUNES, Claudio Pinto.

Reformas educacionais no contexto pós-golpe de 2016. Revista Educação em Debate, Fortaleza, v. 40, p. 162-174, 2018. Disponível em:

http://www.periodicosfaced.ufc.br/index.php/educacaoemdebate/article/view/703. Acesso em: 17 fev. 2017. 
COLARES, M. L. I. S. Políticas educacionais para a formação docente na educação básica. In: EccoS - Rev. Cient., São Paulo, n. 40, p. 67-82, mai./ago. 2016. Disponível em: http://www.redalyc.org/pdf/715/71548306005.pdf. Acesso em 13 mar. 2017.

COSTA, Ana Sheila Fernandes; AKKARI, Abdeljalil; SILVA, Rossana Valéria Souza. Educação básica no Brasil: políticas públicas e qualidade. Revista Práxis Educacional, Vitória da Conquista, v.7, n. 11, jun./dez. 2011. Disponível em: http://periodicos2.uesb.br/index.php/praxis/article/view/666. Acesso em: 14 mar. 2017.

FAPESPA, Fundação Amazônia de Amparo a Estudos e Pesquisas. Barômetro da Sustentabilidade da Amazônia / Diretoria de Estudos e Pesquisas Ambientais. - Belém, 2016.

FAPESPA, Fundação Amazônia de Amparo a Estudos e Pesquisas. Estatísticas Municipais Paraenses: Santarém Diretoria de Estatística e de Tecnologia e Gestão da Informação. - Belém, 2016.

FAPESPA, Fundação Amazônia de Amparo a Estudos e Pesquisas. Mapa de Exclusão Social do Estado do Pará 2016. Diretoria de Estudos e Pesquisas Socioeconômicas e Análise Conjuntural. Disponível em: http://seplan.pa.gov.br/sites/default/files/PDF/loa/loa2017/mapa_de_exclusao_social_do_para_20 16.pdf. Acesso em 13 mar. 2017.

FIGUERÊDO, Livia Almeida; RIBEIRO, Marceli Silva de Souza. Significados da educação integral: a experiência dos professores diante da implantação do programa mais educação. Revista Práxis Educacional, Vitória da Conquista, v. 9, n. 15, jul./dez. 2013. Disponível em: https://periodicos2.uesb.br/index.php/praxis/article/view/745. Acesso em: 11 abr. 2017.

GENÚ, M. A abordagem da ação crítica e a epistemologia da práxis pedagógica. Educação \& Formação, v. 3, n. 9 set/dez, p. 55-70, 3 set. 2018. Doi: https://doi.org/10.25053/redufor.v3i9.856

GOMES-DA-SILVA, P. N. Pedagogia da corporeidade: o decifrar e o subjetivar na educação. Revista Tempos e Espaços em Educação, v. 7, n. 13, p. 15-30, 2014. Disponível em: https://doi.org/10.20952/revtee.v0i0.3255>. Acesso em: 17 abr. 2017.

IBGE, Instituto Brasileiro de Geografia e Estatística. Características urbanísticas do entorno dos domicílios. 2010. Disponível em:

http://www.ibge.gov.br/home/estatistica/populacao/censo2010/entorno/default_entorno.shtm. Acesso em 18 mar. 2017.

IBGE, Instituto Brasileiro de Geografia e Estatística. Estudo das Regiões de Influências de Cidades. 2007. Disponível em: http://www.ibge.gov.br/home/geociencias/geografia/regic.shtm?c=7. Acesso em 18 mar. 2017.

IBGE, Instituto Brasileiro de Geografia e Estatística. Mapas. Disponível em: http://mapas.ibge.gov.br/. Acesso em 18 mar. 2017.

IDESP, Instituto de Desenvolvimento Econômico Social e Ambiental do Pará. Perfil da gestão ambiental dos municípios paraenses: programa municípios verde. Belém, PA: 2011. 
IDESP, Instituto de Desenvolvimento Econômico Social e Ambiental do Pará. Indicadores de qualidade ambiental dos municípios da Região de Integração Baixo Amazonas. Belém, PA: 2013.

INEP, Instituto Nacional de Estudos e Pesquisas Educacionais Anísio Teixeira. Disponível em: http://www.inep.gov.br/. Acesso em 29 mar. 2017.

IPEA, Instituto de Pesquisa Econômica Aplicada. Série Situação Social nos Estados - Pará. Disponível em:

http://www.ipea.gov.br/portal/index.php?option=com_alphacontent\&view=alphacontent\&Itemid= 163. Acesso em 13 mar. 2017.

JACOMELI, Mara Regina Martins. As políticas educacionais da Nova República: do governo Collor ao de Lula. Revista Exitus, v. 1, n. 1, jan./jun. 2011, p. 119-128. Disponível em:

http://www.ufopa.edu.br/portaldeperiodicos/index.php/revistaexitus/article/view/211. Acesso em: 17 abr. 2017.

LARA, A. M. Políticas de redução da desigualdade sociocultural. Educação \& Formação, v. 1, n. 3 set/dez, p. 140-153, 1 set. 2016. Disponível em: https://doi.org/10.25053/edufor.v1i3.1621.

Acesso em: 17 abr. 2017

MARIANO, André Luiz Sena. A aprendizagem da docência no início da carreira: qual política? Quais problemas? Revista Exitus. v. 2, n. 1, jan./jun. 2012, p. 79-94. Disponível em:

http://www.ufopa.edu.br/portaldeperiodicos/index.php/revistaexitus/article/view/67. Acessado em: 17 abr. 2017.

MARÍN, Jorge Garcia. Educación y reproducción cultural: el legado de Bourdieu. Revista Práxis Educacional, Vitória da Conquista, v. 2, n. 2, jan./dez. 2006. Disponível em: https://periodicos2.uesb.br/index.php/praxis/article/view/513. Acesso em: 12 mar. 2017.

NUNES, Claudio Pinto; OLIVEIRA, Dalila Andrade. Trabalho, carreira, desenvolvimento docente e mudança na prática educativa. Educação e Pesquisa, São Paulo, v. 43, p. 65-80, 2017. Disponível em: https://www.scielo.br/scielo.php?pid=S1517-

97022017000100066\&script=sci_abstract\&tlng=pt. Acesso em: 20 ago. 2017.

RODRIGUEZ Linda Grace Matus. La construcción de una identidad docente, ¿un desafío para la política educativa? Revista Exitus. v. 3, n. 1, jan./jun. 2013, p. 75-87. Disponível em:

http://www.ufopa.edu.br/portaldeperiodicos/index.php/revistaexitus/article/view/250. Acesso em: 17 abr. 2017.

RUTKOWSKI, E.W. Desenhando a Bacia Ambiental: subsídios para o planejamento das águas doces metropolitan(izad)as. Tese de Doutorado. Faculdade de Arquitetura e Urbanismo. Universidade de São Paulo. 1999.

SANTARÉM. Histórico. Prefeitura. 2017. Disponível em: http://www.santarem.pa.gov.br. Acesso em 30 mar 2017.

SEMA, Secretaria Meio Ambiente - Pará. Macrozoneamento Ecológico Econômico do Pará. Disponível em: https://www.semas.pa.gov.br/. Acesso em 29 mar. 2017. 
SILVA, Daniela Oliveira Vidal da; BRITO, Vera Lúcia Fernandes de; NUNES, Claudio Pinto. Valorização docente na conjuntura do pós impeachement de 2016 no Brasil. Revista Cocar (online), v. 13, p. 1-20, maio/ago. 2019. Disponível em:

https://periodicos.uepa.br/index.php/cocar/article/view/2518. Acesso em: 19 fev. 2017.

SILVA, Nilson Robson Guedes. Gestão escolar democrática: uma contextualização do tema. Revista Práxis Educacional, Vitória da Conquista, v. 5, n. 6, jan./jun. 2009. Disponível em: http://periodicos2.uesb.br/index.php/praxis/article/view/590. Acesso em: 13 fev. 2017.

SOCORRO, Paulina Elena Villasmil; SANTOS, Arlete Ramos dos; NUNES, Claudio Pinto. Políticas públicas educativas en Latinoamérica: el contexto brasileño y el venezolano. Educação em Questão (online), v. 55, n. 45, p. 12-41, 2017. Disponível em:

https://periodicos.ufrn.br/educacaoemquestao/article/view/12743. Acesso em: 20 nov. 2017.

TANCREDI, Regina Maria Simões Puccinelli. Políticas públicas de formação de professores: o Pibid em foco. Revista Exitus, v. 3, n. 1, jan./jun. 2013, p. 13-31. ISSN 2237-9460. Disponível em: <http://www.ufopa.edu.br/portaldeperiodicos/index.php/revistaexitus/article/view/246> Acessado em: 17 abr. 2017.

TRINDADE JR, S. C.C. da. Das "cidades na floresta" às "cidades da floresta": espaço, ambiente e urbanodiversidade na amazônia brasileira. In: Papers do NAEA. N. 321. Dez. 2013. Belém, PA. Disponível em: http://www.naea.ufpa.br/naea/novosite/paper/215. Acesso em 13 mar. 2017.

\section{SOBRE OS AUTORES:}

\section{Ana Elisa Spaolonzi Queiroz Assis}

Doutora em Educação pela Universidade Estadual de Campinas (Unicamp); professora do Programa de Pós-Graduação em Educação da Unicamp; membro do Laboratório de Políticas Públicas e Planejamento Educacional (LaPPlanE). E-mail: anasqa@unicamp.br

\section{José Roberto Rus Perez}

Doutor em Educação pela Universidade Estadual de Campinas (Unicamp); Pesquisador Visitante Sênior do Programa de Pós-graduação em Educação da Universidade Federal do Oeste do Pará. Professor Livre-docente aposentado da Faculdade de Educação da Unicamp; Pós-doutorado na Universidade do Texas em Austin; membro do Grupo de Estudos e Pesquisas História, Sociedade e Educação no Brasil (HISTEDBR-UFOPA); bolsista FAPESPA; Professor Visitante Sênior. Email: rusperez@uol.com.br

\section{Maria Lília Imbiriba Sousa Colares}

Doutora em Educação pela Universidade Estadual de Campinas (Unicamp); professor do Programa de Pós-Graduação em Educação da Universidade Federal do Oeste do Pará (UFOPA); membro do Grupo de Estudos e Pesquisas História, Sociedade e Educação no Brasil (HISTEDBRUFOPA). E-mail: liliaimbiribacolares@gmail.com 